\title{
Degradação de sacolas plásticas convencionais e oxibiodegradáveis
}

\author{
Degradation of plastic bags conventional and oxybiodegradable
}

\section{Andrise Janaina Follmann, Alexandre Couto Rodrigues, Mariza de Camargo, Diego Nicolau Follmann, Velci Queiróz de Souza e Cristiane Graepin}

\author{
Universidade Federal de Santa Maria, RS, Brasil
}

andri.j@hotmail.com; coutoalexandre@yahoo.com.br; mariza@ufsm.com; diegonicolaufollmann@gmail.com; velciq@gmail.com; cristianegraepin@hotmail.com

\section{Resumo}

O uso de sacolas plásticas é comum no cotidiano das pessoas, porém seu acúmulo no meio ambiente é um problema sério causado pela sociedade moderna. Dessa forma, torna-se fundamental estudar a degradação destas para entender os processos que podem ocorrer quando descartadas indevidamente pela sociedade. Diante disso, sacolas plásticas convencionais e oxibiodegradáveis foram submetidas a exposição às intempéries (chuva, umidade, oscilação de temperatura do ar, radiação solar) sob a areia, para avaliar a degradação natural das amostras em função de suas respectivas perdas de massa. Notou-se que as sacolas convencionais e oxibiodegradáveis apresentaram perda de massa, porém ambas apresentaram comportamento similares frente às intempéries. As sacolas oxibiodegradáveis não apresentaram degradação total durante o período de estudo (12 meses).

Palavras-chave: Sacolas plásticas; Degradação; Oxibiodegradável

\section{Abstract}

The use of plastic bags is common in daily life, but their accumulation in the environment is a serious problem caused by modern society. Thus, it is essential to study the degradation of these to understand the processes that can occur when improperly discarded by society. Thus, conventional and oxybiodegradable plastic bags were subjected to exposure to the elements (rain, humidity, air temperature changes, sunlight) under the sand, to assess the natural degradation of the samples according to their respective mass loss. It was noted that the conventional and oxybiodegradable bags showed weight loss, but both showed similar behavior against the weather. The oxybiodegradable bags showed no overall degradation during the study period (12 months).

Keywords: Plastic bags; Degradation; Oxybiodegradable 


\section{Introdução}

Um dos artefatos mais utilizados pela indústria para produção de bens de consumo é o polímero. Utilizado para a confecção de roupas, meios de transporte, embalagem de alimentos, produção de tintas, eletro-eletrônicos e sacolas plásticas, se tornando indispensável para o ser humano (DE PAOLI, 2008). No entanto, o elevado uso de sacolas plásticas é um problema sério causado pela sociedade moderna. Seu descarte inadequado pode ocasionar muitos prejuízos ao meio ambiente.

Os plásticos são materiais poliméricos sólidos à temperatura ambiente, porém quando submetidos a um aumento de temperatura e pressão podem reagir de forma diferente (SPINACÉ; DE PAOLI, 2005). Os plásticos podem ser biodegradáveis e oxibiodegradáveis. Define-se plástico biodegradável todos os plásticos que são degradáveis através da ação de microrganismos, como por exemplo, bactérias, algas e fungos ou pela ação da luz solar (PINTO et al., 2012). Os plásticos oxibiodegradáveis possuem fabricação diferenciada, apresentam aditivos pró-degradantes que aceleram o processo de degradação, ou seja, quando estes aditivos são incluídos no processo de manufatura normal, eles causam a decomposição do plástico em água, dióxido de carbono e uma pequena quantidade de biomassa, através de uma combinação qualquer de luz, calor e estresse (POLIFILME, 2013; BRITO et al., 2011).

A Norma Brasileira (NBR) de terminologia para embalagens plásticas degradáveis e/ou de fontes renováveis (ABNT NBR 15448-1) ressalta que a degradação é uma alteração na estrutura química do polímero, o que acarreta em uma perda irreversível das propriedades de uso do material. Porém para estudar a degradação de qualquer tipo de polímero devem ser levados em consideração condições ambientais e laboratoriais, os quais indicarão uma degradação já existente ou até mesmo simular uma possível degradação (VIANA; ANTUNES, 2006).

Assim, o material pode tanto ser submetido a um envelhecimento natural (intempéries) quanto artificial (laboratório) e algumas medidas podem ser utilizadas para verificar o nível de degradação. Dentre elas podem ser citadas a avaliação visual do material, a medida da cor superficial, a avaliação das propriedades mecânicas e a avaliação de alterações na estrutura através de métodos espectrométricos (VIANA; ANTUNES, 2006). Mano, Pacheco e Bonelli (2010) descrevem que a degradação causada pelos efeitos das intempéries é um processo complexo e que pode se manifestar em mais de um estágio, pois ela depende de fatores como a exposição à radiação, temperatura, presença de água e de componentes atmosféricos (oxigênio, ozônio, óxido nitroso e hidrocarbonetos).

O processo de oxibiodegradação baseia-se em três estágios, o primeiro refere-se ao início do processo de fabricação, onde se introduz o aditivo específico à resina plástica, estabelecendo-se assim a vida útil do produto. $\mathrm{O}$ segundo estágio relaciona-se ao final da vida útil, onde o produto já começa a degradar-se na presença de oxigênio por um processo de oxidação acelerado pela luz e calor, fazendo com que a cadeia molecular do polímero plástico seja quebrada em cadeias moleculares menores. Por fim, a biodegradação é completada pelos microrganismos sem deixar resíduos nocivos, como metano, pois o processo todo ocorre na presença de oxigênio (RES BRASIL, 2013).

O tempo esperado para decomposição dos plásticos oxibiodegradáveis pode variar de dias até anos, dependendo dos requisitos do produto, ou seja, irá depender das formulações de aditivos e seus diferentes níveis de inclusão no produto final (POLIFILME, 2013).

São atribuídas várias vantagens relacionadas ao uso desta tecnologia, as quais merecem destaque, a reutilização, podem ser destinados a compostagem após o descarte, não emitem metano em sua degradação, dentre outras (POLIFILME, 2013).

Porém, há controvérsias em relação ao uso dessas sacolas plásticas, alguns especialistas relatam que ao se decomporem podem liberar gases geradores de efeito estufa, como dióxido de carbono e metano, metais pesados, pigmentos de tintas e compostos inexistentes no plástico comum (PINTO et al., 2012). Estudos comparativos entre a degradação de sacolas plásticas convencionais e oxibiodegradáveis, expostas a condições naturais de degradação não foram encontradas na literatura.

Os objetivos desse trabalho foram: a) Avaliar a degradação de sacolas oxibiodegradáveis em exposição às intempéries (chuva, umidade, oscilação de temperatura do ar, radiação solar), em condições naturais; b) Avaliar o comportamento das sacolas exibiodegradáveis em comparação a sacolas convencionais.

\section{Materiais e Método}

O experimento foi realizado na Universidade Federal de Santa Maria, Campus de Frederico Westphalen-RS, especificamente na área experimental do curso de Engenharia Florestal. Localizado nas coordenadas $27^{\circ} 23^{\prime} 46^{\prime \prime}$ latitude, 5325'37" longitude, com elevação média de 477 metros do nível do mar.

O clima da região é do tipo subtropical úmido, segundo a Classificação climática de Köppen-Geiger: Cfa, a temperatura média anual é em torno de $18^{\circ} \mathrm{C}$, com máxima no verão podendo atingir $41^{\circ} \mathrm{C}$ e mínima no inverno, atingindo valores inferiores a $0^{\circ} \mathrm{C}$. A precipitação média anual é elevada, geralmente entre 1800 e $2100 \mathrm{~mm}$, bem 
distribuídos ao longo do ano (BERNARDI et al.,2007).

Neste experimento foram utilizados como amostras, dois tipos diferentes de sacolas plásticas. Ambas produzidas com polietileno de alta densidade (PEAD), as quais são utilizadas por comerciantes do norte do Rio Grande do Sul, sendo: sacolas oxibiodegradáveis e sacolas convencionais. A diferença entre as duas é que a sacola oxibiodegradável é fabricada com aditivos pró-degradantes $(\mathrm{d} 2 \mathrm{w})$ e a convencional é uma sacola cuja indicação do rótulo é de apenas ser reciclável (matéria prima proveniente do petróleo).

O experimento teve duração de 12 meses e refere-se à degradação de sacolas plásticas convencionais e oxibiodegradáveis submetidas à exposição de intempéries (chuva, umidade, oscilação de temperatura do ar, radiação solar), em ambiente natural.

A condução deu-se em blocos ao acaso (DBC), no qual os tratamentos foram distribuídos ao acaso, dentro do controle local bloco. Desta forma, foi composto por um esquema fatorial $2 \times 4$, onde respectivamente corresponde ao tipo de sacola versus tempo de exposição (T.E.), sendo composto por dez tratamentos, três repetições. Totalizando trinta unidades experimentais.

A condição ambiental do experimento foi representada em superfície de recipientes de polietileno contendo areia. Este material foi utilizado para simular uma situação ambiental na qual, as sacolas plásticas podem ser depositadas, por ou sem intervenção humana.

Assim, foram coletadas sacolas plásticas fabricadas recentemente, as quais foram cortadas em pequenos quadrados com área superficial de 0,0225 $\mathrm{m} 2$ cada. Após as mesmas foram pesadas em uma balança analítica digital (modelo Ay-220, marca SHIMADZU), onde se aferiu suas respectivas massas, para posterior comparação em função dos diferentes tempos de exposição.

As unidades experimentais foram compostas por recipientes de polietileno (capacidade de $12 \mathrm{~L}$ ). Os quais foram enumerados conforme cada bloco, para facilitar a identificação. Após, preencheu-se os recipientes com $15 \mathrm{~cm}$ de areia e por fim procedeu-se a fixação das sacolas à superfície, com auxílio de pregos para que pudessem sofrer ação direta dos agentes naturais (chuva, vento e sol).

A metodologia para coleta de dados baseou-se na avaliação das amostras de sacolas em épocas (inicial, três, seis, nove e doze meses). Em cada época de avaliação, as devidas amostras foram fotografadas, retiradas dos baldes com auxílio de uma pinça, colocadas em um suporte e levadas ao laboratório onde foram cuidadosamente limpas para realização das devidas análises. Após, as sacolas tiveram sua massas aferidas com a mesma balança analítica digital, utilizada no início do experimento.

Assim, para proceder à verificação do nível de degradação das amostras, analisou-se a degradação de cada amostra em porcentagem. Após, obtidas as massas de cada uma das amostras, a degradação das mesmas puderam ser expressas pelo percentual de perda de massa (Equação 1). Em que, W0 e W1 são massas das amostras (g) antes e após a degradação, respectivamente (CASARIN; SOUZA JÚNIOR; AGNELLI, 2013).

\section{Perda de massa $(\%)=\frac{(w 0-w 1)}{w 0} \times 100 \%$}

Após a coleta dos dados, procedeu-se o seu processamento submetendo-se as médias à análise de variância pelo teste $\mathrm{F}$, a $5 \%$ de probabilidade de erro. As análises estatísticas foram realizadas pelo programa computacional Excel 2013 e Genes (CRUZ, 2013).

\section{Resultados e Discussão}

Avaliou-se a degradação natural das amostras em função de suas respectivas perdas de massa. Notou-se que tanto as sacolas plásticas convencionais quanto as oxibiodegradáveis apresentaram perda de massa significativa em todas as amostras submetidas ao intemperismo, sob a areia (Figura 1).

Caraschi, Ramos e Leão (2002) também utilizaram dentre os critérios para avaliar a degradação natural a determinação da perda de massa. No estudo utilizaram amostras de polihidroxibutirato (PHB), um plástico biodegradável e compósitos de $\mathrm{PHB} /$ madeira, sendo que os outros parâmetros analisados foram o aspecto estrutural e a mudança de coloração.

A perda de massa tanto para as sacolas plásticas convencionais quanto as oxi-biodegradáveis é resultado dos fatores climáticos, os quais tiveram ação direta sob as sacolas durante todo o período de experimento. Esses fatores estão associados aos processos de degradação que ocorrem nas sacolas plásticas, que segundo Mano, Pacheco e Bonelli (2010) são a fotodegradação e a degradação térmica.

A fotodegradação baseia-se na forma mais intensa de degradação que pode ocorrer com os resíduos plásticos, pois está associada aos efeitos da radiação solar juntamente com a presença de oxigênio. Esse processo pode ocorrer pela ação conjunta de forças, como vento e chuva, fazendo com que ocorra uma diminuição do peso molecular e 
fissuras nas superfícies moldadas, tornando os plásticos quebradiços e esfarelados, gerando pequenos fragmentos (MANO; PACHECO; BONELLI, 2010).

Já a degradação térmica é um processo causado pela ação da temperatura sobre o material, ou seja, com o seu aumento ou diminuição é mais provável que ocorram cisões químicas nos polímeros, devido aos choques de temperatura. Como consequência ocorrerá uma diminuição na estabilidade dimensional e na resistência dos plásticos, além de uma mudança perceptível de coloração (MANO; PACHECO; BONELLI, 2010).

Contudo, Costa (2012) indica outro processo que também pode influenciar na degradação dos plásticos, a biodegradação. Um processo que ocorre pela ação de microrganismos presentes no meio ambiente, ao qual, enzimas específicas quebram a cadeia polimérica digerindo-a.
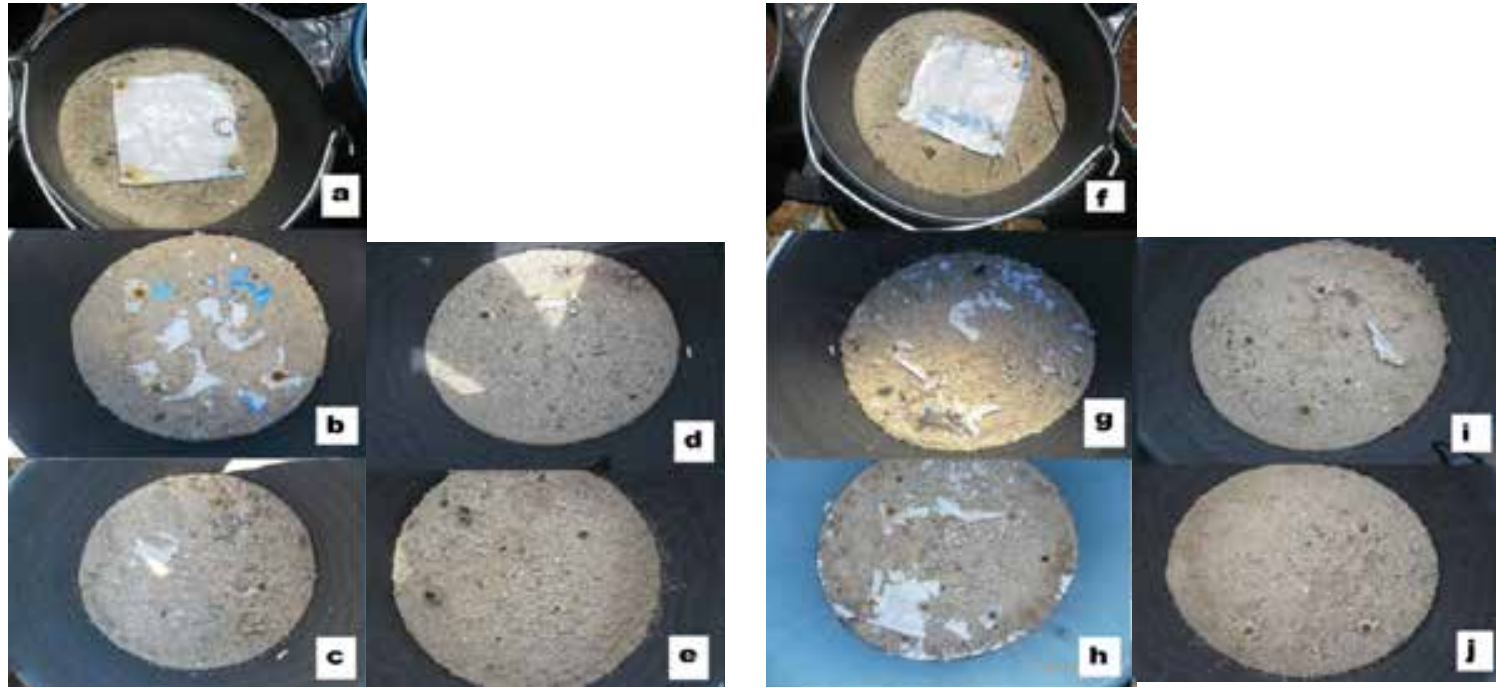

Figura 1 - Fotografia das sacolas oxibiodegradáveis [a) Inicial. b) 90 dias. c) 180 dias. d) 270 dias. e) 360 dias] e convencionais [f) Inicial. g) 90 dias. h) 180 dias. i) 270 dias. j) 360 dias].

Em estudo semelhante, Mothé, Dias e Mothé (2009) avaliaram a degradação térmica de sacolas de poli (ácido láctico), PLA biodegradável e de polietileno de alta densidade (PEAD) não biodegradável, submetidos a temperaturas de até $800^{\circ} \mathrm{C}$. Os autores notaram que a perda de massa dos materiais foi praticamente a mesma, em torno de $98 \%$.

Em estudos realizados por Santos, Patrício e Aroeira (2013) avaliou-se a degradação de sacolas de polietileno tradicional, biodegradável, oxibiodegradável e reciclada em condições controladas de laboratório. Os autores não obtiveram uma degradação significativa para nenhuma das sacolas estudadas em um período de incubação de 180 dias. Resultados que indicam que as sacolas oxibiodegradáveis não degradaram mais rápido do que aquelas de polietileno tradicional.

Em um trabalho desenvolvido por Menk (2012), avaliou-se a degradação de sacolas oxibiodegradáveis e convencionais em solo simulado por um período de noventa dias. Ao término deste, nenhuma das amostras apresentaram perda de massa significativa, apenas alterações nas propriedades mecânicas (tensão e resistência).

No presente estudo analisa-se também, que a degradação foi mais acentuada em período inicial de exposição ao intemperismo (três meses), pois ocorreu degradação de aproximadamente $55 \%$ para as duas sacolas. Esse resultado pode ter ocorrido devido aos três primeiros meses, ter predominado a estação do verão (dezembro a fevereiro), com temperaturas elevadas e maior insolação diária (Figura 2). Esse fator pode ter influenciado diretamente na degradação das sacolas plásticas, tanto convencionais quanto oxibiodegradáveis.

O gráfico da Figura 2 refere-se às médias das temperaturas máximas registradas, no período de dezembro de 2012 a julho de 2013, pela estação automática do Instituto Nacional de Meteorologia (INMET), que se localiza no campus da UFSM/FW.

Situação semelhante ocorreu em um estudo realizado por Dalmolin (2007), com sacolas plásticas de PE, expostas às intempéries pelo período de um ano. Em apenas 70 dias de exposição, a massa molar do polietileno diminui em torno de $40 \%$, chegando a $95 \%$ em 140 dias de exposição ao intemperismo.

A variável tempo de exposição foi significativa a 5\% de probabilidade de erro sendo efetuada assim a análise de regressão polinomial de segundo grau (Figura 3). A degradação das sacolas plásticas convencionais pode ser explicada pela regressão $(Y=5,3186+14,858 x-0,6329 x 2)$, e a degradação das sacolas plásticas oxibiodegradáveis é explicada pela regressão $\left(Y=1,9188+14,768 x-0,6051 x^{2}\right)$. Esse comportamento indica constante degradação, no entanto, durante o período avaliado (12 meses), não ocorreu degradação total de ambos os matérias estudados. 


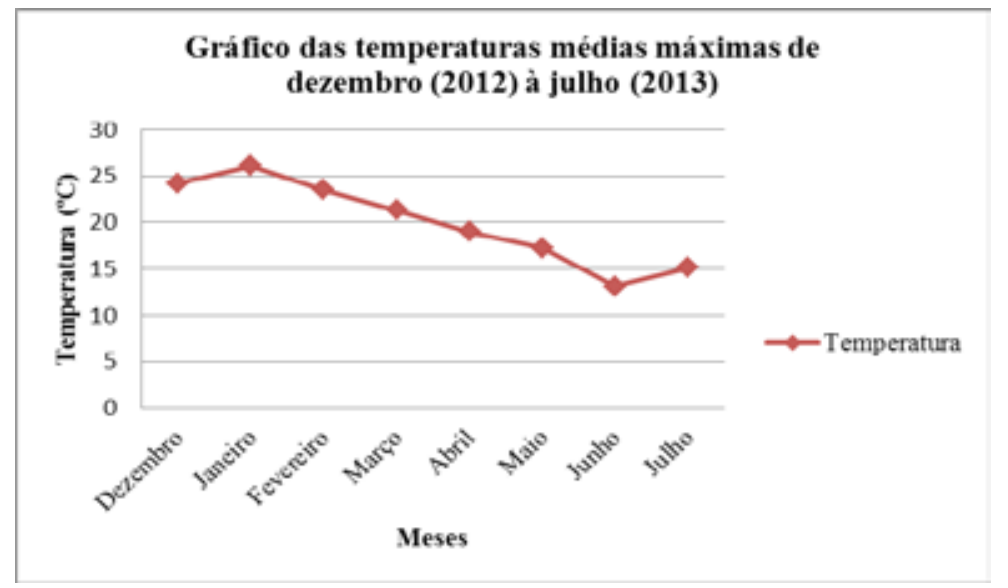

Figura 2 - Gráfico das temperaturas médias máximas para os meses de dezembro de 2012 a julho de 2013 Fonte: www.inmet.gov.br/
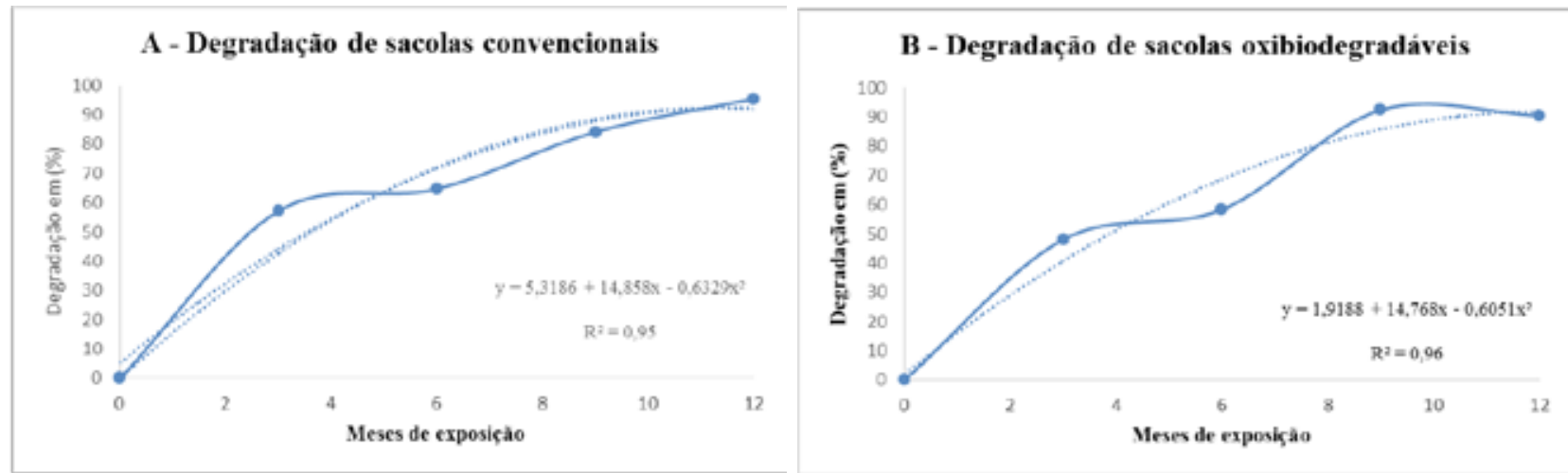

Figura 3 - Degradação de sacolas (\%) convencionais (A) e oxibiodegradáveis (B), devido à exposição a intempéries ambientais, durante o período de 12 meses, Frederico Westphalen, 2016

Dessa forma, os resultados analisados demonstram que o material oxibiodegradável não apresenta degradação mais rápida do que o material convencional, indicando a necessidade de um estudo contínuo e de maior duração, para verificar os efeitos da incorporação do aditivo em tempo maior de exposição, assim como simular o favorecimento de condições ideais para a ação dos microrganismos sobre as sacolas plásticas.

\section{Conclusão}

Conclui-se que houve degradação de sacolas oxibiodegradáveis e convencionais em exposição às intempéries climáticas, porém as sacolas oxibiodegradáveis não apresentaram comportamento mais acelerado na degradação quando comparadas ao processo de degradação das sacolas convencionais, nessas condições de estudo. Também foi possível concluir que as sacolas oxibiodegradáveis ao final do experimento não degradado totalmente.

\section{Agradecimentos}

Os autores agradecem ao apoio financeiro recebido através de bolsa Reuni, à Universidade Federal de Santa Maria, campus de Frederico Westphalen, especialmente aos professores envolvidos no projeto e aos demais colegas e funcionários colaboradores, que participaram da elaboração e execução deste trabalho.

\section{Referências}

ABNT. Associação Brasileira De Normas Técnicas. (2008). NBR 15448-1: Embalagens plásticas degradáveis e/ou renováveis - Parte 1: Terminologia. 
Bernardi, I. P., Pulchério-Leite, A., Iranda, J.M.D. \& Passos, F. C. (2007). Ampliação da distribuição de Molossops neglectus Williams e Genoways (Chiroptera, Molossidae) para o Sul da América do Sul. Revista Brasileira de Zoologia, 24(2), 505-507. Disponível em:<http://www.readcube.com/articles/10.1590/S0101-81752007000200032?locale=en>. Acesso em: 16 jan. 2014.

Brito, G. F, Agrawal, P., Araújo, E. M., Mélo, T. J. A. (2011). Biopolímeros, Polímeros Biodegradáveis e Polímeros Verdes. Revista Eletrônica de Materiais e Processos, 6(2), 127-139. Disponível em:< http://www.dema.ufcg.edu.br/revista/index. php/REMAP/article/viewFile/222/204>. Acesso em: 09 out. 2013.

Caraschi, J. C.; Ramos, U. M.; Leão, A. L. (2002). Compósitos biodegradáveis de polihidroxibutirato (PHB) reforçado com farinha de madeira: propriedades e degradação. Universidade Estadual de Maringá, 24(6), 1609-1614. Disponível em:< http://www.periodicos.uem.br/ojs/index.php/ActaSciTechnol/article/view/2475/0>. Acesso em: 21 dez. 2013.

Casarin, S. A.; Souza Júnior, O. F.; Agnelli, J. A. M. Avaliação da biodegradação de sacolas plásticas. Revista SODEBRAS, 2013;8:26-29. Disponível em:< http://www.sodebras.com.br/edicoes/N87.pdf>. Acesso em: 17 dez. 2013.

Costa, C. S. Avaliação da biodegradação de compósitos de poli (3-hidroxibutirano)/nanopatículas obtidas a partir de farelo de milho, 2012. Disponível em:<http://monografias.poli.ufrj.br/monografias/monopoli10004442.pdf>. Acesso em: 09 out. 2013.

Cruz, C. D., (2013). Genes - a software package for analysis in experimental statistics and quantitative genetics. Acta Scientiarum. Agronomy, 35, 271-276.

Dalmolin, E. Avaliação da degradação de polietilenos contendo aditivo pró-degradante. [Dissertação]. Porto Alegre: Universidade Federal do Rio Grande do Sul; 2007. 74 p. Disponível em:< http://www.lume.ufrgs.br/bitstream/ handle/10183/11123/000605512.pdf?sequence=1>. Acesso em: 18 dez. 2013.

De Paoli, M. A. Degradação e estabilização de polímeros. (2008). Chemkeys 2 2 versão on-line. Disponível em:<http://www. chemkeys.com/blog/wp-content/uploads/2008/09/polimeros.pdf >. Acesso em: 07 out. 2013.

Instituto Nacional de Meteorologia - INMET [Internet]. Disponível em:<http://www.inmet.gov.br/portal/>.

Manno, E. B.; Pacheco, É. B. A. V.; Bonelli, C. M. C. Meio ambiente, poluição e reciclagem, 2 ed., Blucher; 2010.

Menk, T. A. Avaliação da biodegradação de embalagens Plásticas comerciais denominadas Oxi(bio)degradáveis em solo simulado [Trabalho de Conclusão de Curso]. Sorocaba: Faculdade de Tecnologia de Sorocaba; 2012. 63 p. Disponível em:<http://fatecsorocaba.edu.br/principal/pesquisas/nuplas/dissertacoes/TCCs1sem2012/Tha\%C3\%ADs\%20de\%20 Almeida\%20Menk.pdf.>. Acesso em: 23 dez. 2013.

Mothé, C. G.; Dias F. T. G.; Mothé, M. G. N. (2009). Avaliação térmica e mecânica da degradação de Materiais poliméricos na proteção ao meio Ambiente, Em: Congresso Brasileiro De Polímeros , 10, CBPOL. Disponível em:<http://www.abpol. org.br/cbpol2.php>. Acesso em: 10 out. 2013.

Pinto, J. C.; et. al. (2012). Impactos ambientais causados pelos plásticos: uma discussão abrangente sobre os mitos e os dados científicos. E-papers, (2), 296. Disponível em:<http://books.google.com.br/books. Acesso em: 04 dez. 2013.

Polifilme embalagens [Internet]; 2013 Dez 16. Disponível em:<http://polifilme.com.br/index.php>.

Res Brasil [Internet]; 2013 Dez 16. Disponível em:<http://www.resbrasil.com.br/index.php>.

Santos, V. P; Patrício, P. S. O; Aroeira, B. M. (2013). Estudo comparativo da degradação em solo de diferentes tipos de sacolas plásticas. Em: Congresso Brasileiro De Polímeros, 12, CBPOL, p. 22-26. Disponível em:< http://www.eventweb. com.br/cbpol/home event/schedule.php?q=\&area=\&busca_por=\&sessao=978>. Acesso em: 11 out. 2013.

Spinacé, M. A. S; De Paoli, M. A. A tecnologia da reciclagem de polímeros. (2005). Química Nova, 28(1), 65-72. Disponível em:<http://www.scielo.br/scielo.php?script=sci_arttext\&pid=S0100-40422005000100014>. Acesso em: 18 mai. 2013.

Viana, H. M.; Antunes, R. A Degradação de Polímeros: Degradação de Polímeros e Corrosão, 2006. Disponível em: <http:// www3.fsa.br/LocalUser/Materiais/deg_intro.pdf>. Acesso em: 09 out. 2013. 